\title{
Application of Aluminum Sulfate in the Treatment of Papermaking White Water
}

\author{
Xianglan Ming, ${ }^{\mathrm{a}}$ Qichao Li, ${ }^{\mathrm{a}}$ and Wei Jiang ${ }^{\mathrm{b}, *}$ \\ Physical chemical methods were used to treat papermaking white water \\ used to produce plant fiber mulch sheet that contained fine fibers and \\ inorganic fillers as suspended solids. The ordinary chemical oxygen \\ demand $\left(\mathrm{COD}_{\mathrm{cr}}\right)$ was obviously reduced after the papermaking white \\ water was treated by the flocculant. By comparing three different \\ coagulants (aluminum sulfate $\left(\mathrm{Al}_{2}\left(\mathrm{SO}_{4}\right)_{3}\right)$, poly-aluminum chloride (PAC), \\ and poly(diallyldimethylammonium chloride) (PDADMAC)) and flocculant \\ (poly-acrylamide copolymer (PAM)) to process papermaking white water, \\ it was found that $\mathrm{Al}_{2}\left(\mathrm{SO}_{4}\right)_{3}$ had the best coagulation effect and the lowest \\ cost. The best flocculation conditions were $2,733 \mathrm{mg} / \mathrm{L}$ of $\mathrm{Al}_{2}\left(\mathrm{SO}_{4}\right)_{3}$ and \\ $4.52 \mathrm{mg} / \mathrm{L}$ of PAM to treat the papermaking white water. Under the best \\ flocculation conditions, the CODcr was less than $300 \mathrm{mg} / \mathrm{L}$. The goal of \\ closed recycling and zero discharge of white water in the production \\ process of plant fiber mulch sheet was realized.
}

Keywords: Papermaking white water; Physical chemical method; Flocculation; Aluminum sulfate

Contact information: a: College of Mechanical and Electrical Engineering, Lingnan Normal University, Zhanjiang 524048, China; b: College of Information Engineering, Lingnan Normal University, Zhanjiang 524048, China; *Corresponding author: jwlingnan@ 163.com

\section{INTRODUCTION}

In order to strengthen the control of pollutants and protect the human environment, the Ministry of Environmental Protection of the People's Republic of China implemented the standard GB 3544-2008 (2008), "Discharge standard of water pollutants for pulp and paper industry". The standard requires existing pulp and paper companies to implement the upper limit of water pollutant emissions. According to the standard GB 3544-2008 (2008), the common chemical oxygen demand $\left(\mathrm{CODCr}_{\mathrm{Cr}}\right.$ ) has a limit of 80 to $100 \mathrm{mg} / \mathrm{L}$, and the fiveday biological oxygen demand (BOD5) has a limit of $20 \mathrm{mg} / \mathrm{L}$. The standard GB 35442008 (2008) also adds indicators for water pollutants such as nitrogen, phosphorus, adsorbable organic halides (AOX), and chroma (Wang et al. 2007; Mänttäri and Nyström 2010; Huang et al. 2012; Mänttäri et al. 2015; Zhao et al. 2016; Toczyłowska-Mamińska 2017; Wang et al. 2018).

Domestically made chemical pulp, especially wet pulp (under $10 \%$ consistency), has an anionic trash content that is typically 1 to 5 times higher than that of imported chemical mechanical pulp, such as Canada-Crystal brand and other high-quality brands of bleached chemical thermomechanical pulp (BCTMP) (Agarwal et al. 2001; Avci et al. 2002; Sui et al. 2007; Wang et al. 2014; Sun et al. 2018). The higher anionic trash containing pulp will cause low fiber retention of paper machines and difficulties in sizing with alkylketene dimer (AKD) or alkenylsuccinic anhydride (ASA). The higher anionic trash containing pulp can cause excessive foam in the white water system and the buildup of sediment in the stock and white water systems. The higher anionic trash containing pulp 
will result in unstable production, more frequent paper breaks, and reduced paper strength and uniformity (Gao et al. 2005; Li et al. 2010; Zhan et al. 2010). As the white water system in a paper machine becomes more closed, the problem tends to be aggravated, so it is urgent to deal with the anionic waste of chemical pulp.

Currently, advanced methods used to treat papermaking white water primarily include the biochemical method and the physical chemical method (Culp et al. 1978; Watkinson et al. 2007; Senta et al. 2011; Wu et al. 2011). On the basis of much engineering practice, physical chemical methods have become widely adopted. Physical chemical methods generally are simple and convenient, with a high efficiency and a low investment cost. Such methods can effectively remove the fine fibers, suspended solid, chroma, and organic content in the recycled papermaking white water. The obtained pulp slurry can also be used to produce boxboard after proper treatment. The treated supernatant can be recycled as industrial water. Therefore, its economic and environmental benefits are quite significant (Yeon et al. 2005; Toyoda et al. 2011; Lüeddeke et al. 2015; Rayne and Ikonomou 2015). A large amount of white water gets produced in a papermaking process, which accounts for a large proportion of the total industrial wastewater and it contains a large amount of soft fibers, fillers, and suspended solids. Thus, the pollution it causes has attracted worldwide attention. In general practice, most of the paper mills' white water produced in forming section is recovered and sent to the stock preparation section to fan pump through dilution line, and only part of the flow is rejected and goes for the white water treatment (Hubbe et al. 2016; Wei 2016). To treat papermaking white water, it is first filtered in a save-all device to recover the cellulosic fines to reduce the content of the suspended solids. Subsequently, flocculants and coagulants are added to coagulate the remaining fine fibers, fillers, colloidal substances, and partially soluble organic matter in the white water. After settling of the solids in a clarifier, the treated clarified water can be completely reused for production (Wang et al. 2006; Gao and Li 2007; Shi 2010; Yang and Wang 2010; Xie et al. 2012; Zhao et al. 2014).

In this work, the sludge settling effect was studied by comparing the three coagulants (aluminum sulfate $\left(\mathrm{Al}_{2}\left(\mathrm{SO}_{4}\right)_{3}\right)$, polybasic aluminum chloride (PAC), polydimethyldiallyl ammonium chloride (PDADMAC)), and the anionic polyacrylamide (PAM) flocculant to treat white water used to produce plant fiber mulch sheet. The influence of the different coagulants on the flocculation effect was examined. In order to provide the theoretical basis and technical support for the appropriate physical chemical methods for the advanced treatment of the papermaking white water used to produce plant fiber mulch sheet, the experiments were conducted to screen out the suitable flocculant system, to compare the effects of the different flocculants and coagulant additives on the treatment of the papermaking white water. The optimal conditions for the reaction were analyzed and evaluated. The goal of closed recycling and zero discharge of white water in the production process of plant fiber mulch sheet is realized.

\section{EXPERIMENTAL}

\section{Materials}

The three coagulants used were $\mathrm{Al}_{2}\left(\mathrm{SO}_{4}\right)_{3}$ (15.6\% solids based on $\mathrm{Al}_{2} \mathrm{O}_{3}$ mass fraction) (Mudanjiang Xinxing Chemical Plant, Mudanjiang, China), poly-aluminum chloride (PAC) (30\% solids based on $\mathrm{Al}_{2} \mathrm{O}_{3}$ mass fraction) (Zibo Taihua Fine Chemical Co., Ltd., Zibo, China), and poly (diallyldimethylammonium chloride) (PDADMAC) 
(solid) (Nantong Runfeng Petrochemical Co., Ltd., Nantong, China). The flocculant used was a poly-acrylamide copolymer (PAM) (solid, positive charge, relative molecular mass 8 million, formulated into $0.3 \%$ aqueous solution for use) (Dezhou Ruixing Water Purification Material Co., Ltd., Dezhou, China). The water sample used for the water quality index of the papermaking white water was taken from a paper mill in the Heilongjiang province of China that produced plant fiber mulch sheet. The $\mathrm{pH}$ of white water was between 7.5 and 7.8, the chemical oxygen demand ( $\mathrm{CODCr}$ ) was 640 to 872 $\mathrm{mg} / \mathrm{L}$, and the suspended solid was 160 to $193 \mathrm{mg} / \mathrm{L}$. The solids content of white water was $2.13 \mathrm{~g} / \mathrm{L}$. The chemicals used in the papermaking process included the sizing agent dispersed gum rosin, aluminum sulfate, and wet-strength agent (water-soluble, cationic, polyamide polyamine epichlorohydrin resin (PPE)). The type of pulp was a mixture of 30\% rice straw fiber pulp and $70 \%$ kraft wood fiber pulp (KP). The cationic demand of the white water was $56.1 \mu \mathrm{eq} / \mathrm{g}$ (PCD-03 Particle Charge Tester, Mütek, Germany). The zeta potential of white water was $-22.3 \mathrm{mV}$ (SZP-06 Zeta Potentiometer, Mütek, Germany). The reagents required for the $\mathrm{COD}_{\mathrm{Cr}}$ test were concentrated sulfuric acid (Jiangcheng Chemical Co., Ltd., Wuhan, China), potassium hydrogen phthalate standard solution (Guangdong Wengjiang Chemical Reagent Co., Ltd., Shaoguan, China), special oxidizer, special catalyst, and masking agent.

For preparation of the special oxidizer, a balance was used to accurately weigh 20 g aluminum potassium sulfate (Dezhou Ruixing Water Purification Material Co., Ltd., Dezhou, China), 13g potassium dichromate (Dezhou Ruixing Water Purification Material Co., Ltd., Dezhou, China), and 5 g ammonium molybdate (Dezhou Ruixing Water Purification Material Co., Ltd., Dezhou, China). The weighed substances were placed into a $500 \mathrm{~mL}$ beaker and first dissolved with about $200 \mathrm{~mL}$ of distilled water; then $100 \mathrm{~mL}$ of concentrated sulfuric acid was added, and the temperature was allowed to cool to room temperature. The solution was transferred to a $500 \mathrm{~mL}$ volumetric flask and shaken. Regarding the special catalyst, 4.2 g silver sulfate was weighed (Dezhou Ruixing Water Purification Material Co., Ltd., Dezhou, China) with a balance, placed into a $500 \mathrm{~mL}$ volumetric flask, dissolved with concentrated sulfuric acid, and diluted to the mark. The prepared solution was stored for 2 to 3 days to make it completely dissolved before use.

For preparation of the masking agent, $20 \mathrm{~g}$ mercury sulfate was weighed (Jinan Yuanyi Environmental Protection Technology Co., Ltd., Jinan, China) with a balance, placed into a $100 \mathrm{~mL}$ volumetric flask, dissolved with the addition of about $80 \mathrm{~mL}$ of distilled water. Then $10 \mathrm{~mL}$ of concentrated sulfuric acid was slowly added, distilled water to the mark, and shaken with a stopper. All these chemicals were laboratory grade. Triple distilled water was used to prepare all the solutions.

\section{Flocculation Experiment}

For the comparison of the sludge settling performance of the different flocculant systems, $500 \mathrm{~mL}$ of raw water sample was added to a $1,000 \mathrm{~mL}$ graduated cylinder. The sample was agitated with an electromagnetic stirrer (HMS-901; Shenzhen Boda Jingke Biological Technology Co., Ltd., Shenzhen, China). Different amounts of flocculant and an appropriate amount of coagulant were added and mixed with the water at a speed of 200 $\mathrm{r} / \mathrm{min}$ for $2 \mathrm{~min}$. The stirrer was then slowed to $50 \mathrm{r} / \mathrm{min}$ for $10 \mathrm{~min}$ before the stirring was finished. The solution was allowed to stand for $22 \mathrm{~min}$, and the sludge volume fraction was observed at $0,2,6,10,14,18$, and 22 min intervals. Sludge volume fraction $=$ volume of suspended solids in mixed liquid / total volume of mixed liquid $\times 100 \%$.

Ming et al. (2021). "Al$\left(\mathrm{SO}_{4}\right)_{3}$ treatment of whitewater," BioResources 16(1), 1382-1393. 1384 
According to the single-factor pre-experiment results and economics (the price of $\mathrm{Al}_{2}\left(\mathrm{SO}_{4}\right)_{3}$ is half the cost of PAC), the $\mathrm{Al}_{2}\left(\mathrm{SO}_{4}\right)_{3}$ and PAM flocculant system had the lowest cost and the best effect in the treatment of papermaking white water. The central composite design approach was used to study the effects and interaction of the $\mathrm{Al}_{2}\left(\mathrm{SO}_{4}\right)_{3}$ and the PAM on the $\mathrm{COD}_{\mathrm{Cr}}$ of the papermaking white water. There were five levels of $\mathrm{Al}_{2}\left(\mathrm{SO}_{4}\right)_{3}(669$ to $2931 \mathrm{mg} / \mathrm{L})$ and PAM (1.17 to $\left.6.83 \mathrm{mg} / \mathrm{L}\right)$. The ranges and levels of the independent variables are shown in Table 1. During the test, the $\mathrm{pH}$ of papermaking white water was 7.5 .

Table 1. Central Composite Design for Two Variables at Five Levels

\begin{tabular}{|c|c|c|}
\hline \multirow{2}{*}{ Level } & \multicolumn{2}{|c|}{ Factors } \\
\cline { 2 - 3 } & $\begin{array}{c}\mathrm{Al}_{2}\left(\mathrm{SO}_{4}\right)_{3} \\
x_{1}(\mathrm{mg} / \mathrm{L})\end{array}$ & $\begin{array}{c}\mathrm{PAM} \\
x_{2}(\mathrm{mg} / \mathrm{L})\end{array}$ \\
\hline-2 & 669 & 1.17 \\
\hline-1 & 1000 & 2.00 \\
\hline 0 & 1800 & 4.00 \\
\hline 1 & 1600 & 6.00 \\
\hline 2 & 2931 & 6.83 \\
\hline
\end{tabular}

\section{COD $\mathrm{cr}$ Determination}

The CODCr determination was conducted according to a closed catalytic digestion method. Three $\mathrm{mL}$ of distilled water was used as a blank sample. If the concentration of the sample was too high, it was diluted. The diluted water sample was centrifuged at 6,000 $\mathrm{r} / \mathrm{min}$ for $10 \mathrm{~min}$, and $3 \mathrm{~mL}$ of the supernatant was taken for measurement. One $\mathrm{mL}$ each of masking agent and special oxidant were added to each reaction tube. Five $\mathrm{mL}$ of special catalyst was also added to each reaction tube, and the samples were shaken well. The reaction tubes were inserted into the furnace. The solution in the reaction tubes began to digest at a temperature of $165^{\circ} \mathrm{C}$. After a digestion period of $10 \mathrm{~min}$, the reaction tubes were removed and placed on a test tube rack and cool to room temperature. Two $\mathrm{mL}$ of distilled water was added to the reaction tube after the digestion period. The sum of the masking agent and the finishing water was $3 \mathrm{~mL}$. The reaction tube was covered with a stopper and shaken well. If there was precipitation in the sample, the supernatant was measured while at a standstill. The colorimetric method was used to determine the absorbance of the water sample at a wavelength of $610 \mathrm{~nm}$. The CODCr value of the diluted sample was calculated according to the standard curve equation and then multiplied by the dilution factor to obtain the CODCr value of the fermentation broth.

\section{Statistical Analysis}

The experimental results were processed with Microsoft Excel 2010 (Redmond, WA), Design Expert 6.0.10.0 (Stat-Ease, Minneapolis, MN), and Origin Pro 9 software (OriginLab, Northampton, MA) (Shi and He 2003; Ay et al. 2009; Montgomery 2017). The multivariate regression analysis, the optimization process, and the analysis of variance (ANOVA) test were performed using the Design Expert software. The optimum values of the independent variables were determined by conducting three-dimensional response surface analysis of the independent and dependent variables (Sen and Swaminathan 2004; Ravikumar et al. 2005; Tavares et al. 2009; Chen et al. 2015; Ming et al. 2019; Ming and Chen 2020). The detailed experimental design is shown in Table 2. 


\section{RESULTS AND DISCUSSION}

\section{Comparison of the Sludge Settling Performance of Different Flocculant Systems}

Physical chemical methods are used to treat wastewater. The sedimentation performance of sludge is one of the most important indicators for the selection of flocculants. The sedimentation performance affects the wastewater treatment effect and the sludge disposal. When the $\mathrm{Al}_{2}\left(\mathrm{SO}_{4}\right)_{3}, \mathrm{PAC}$, and PDADMAC $(1,800 \mathrm{mg} / \mathrm{L})$ coagulants were used in conjunction separately with the PAM $(4 \mathrm{mg} / \mathrm{L})$ flocculant, the sedimentation performance of the sludge was as shown in Fig. 1.

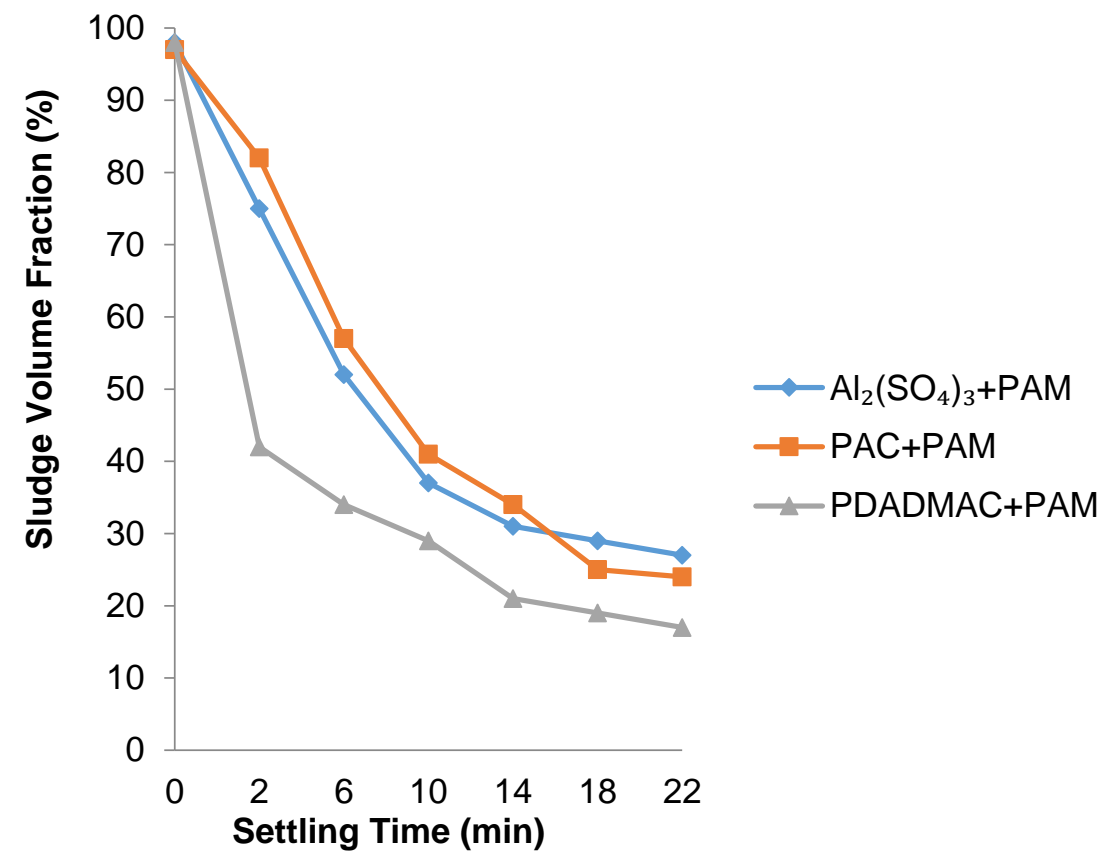

Fig. 1. Comparison of the sludge settling performance. The dosage of the $\mathrm{Al}_{2}\left(\mathrm{SO}_{4}\right)_{3}, \mathrm{PAC}$, and the PDADMAC was $1,800 \mathrm{mg} / \mathrm{L}$, and the dosage of the PAM was $4 \mathrm{mg} / \mathrm{L}$.

According to the flocculation theory, the longer the molecular chain, the higher the degree of connection between particles in the suspension. The larger the expansion space of the flocculant in the water, the more distant particles can be bridged. The more chances of collision with particles, the formation of relatively long and stable bridges and networks. The higher the cationic degree, the stronger the adsorption. Therefore, it is easier to adsorb on the surface of two or more negatively charged colloids or particles, and then form a network, with the help of the adsorption of colloidal particles and mechanical retention to form large floccules. As can be seen in Fig. 1, when the three coagulants were used separately with the PAM to treat the papermaking white water, the $\mathrm{Al}_{2}\left(\mathrm{SO}_{4}\right)_{3}+\mathrm{PAM}$ and the PAC + PAM had an equivalent effect on the sludge settling speed. The PDADMAC + PAM had a detrimental effect on the sludge settling speed. However, the price of $\mathrm{Al}_{2}\left(\mathrm{SO}_{4}\right)_{3}$ is 750 a ton, which is twice cheaper than PAC (1450 a ton). Therefore, this study investigated the combined flocculation effect of $\mathrm{Al}_{2}\left(\mathrm{SO}_{4}\right)_{3}$ and PAM. As a coagulant, aluminum sulfate mainly destabilizes the colloids in the white water. The colloidal particles agglomerate with each other and form larger-particle flocs through adsorption and bridging. 


\section{Effect of Different Additions on the Flocculation Effect}

Regression models

Sixteen experiments were carried out to study the effects and interactions of the $\mathrm{Al}_{2}\left(\mathrm{SO}_{4}\right)_{3}$ and PAM on the CODCr of the papermaking white water (Ming 2016). These are represented in Table 2. Table 2 also shows the values of the papermaking white water $\mathrm{COD}_{\mathrm{Cr}}$ at each of the experimental designed conditions.

Table 2. Experimental Design and Results

\begin{tabular}{|c|c|c|c|}
\hline No. & $\begin{array}{c}\mathrm{Al}_{2}\left(\mathrm{SO}_{4}\right)_{3} \\
x_{1}(\mathrm{mg} / \mathrm{L})\end{array}$ & $\begin{array}{c}\mathrm{PAM} \\
x_{2}(\mathrm{mg} / \mathrm{L})\end{array}$ & \begin{tabular}{c}
$\mathrm{COD}(\mathrm{mg} / \mathrm{L})$ \\
\hline
\end{tabular} \\
\hline 1 & 1000 & 2.00 & 533.192 \\
\hline 2 & 2600 & 2.00 & 326.648 \\
\hline 3 & 1000 & 6.00 & 528.889 \\
\hline 4 & 2600 & 6.00 & 305.133 \\
\hline 5 & 669 & 4.00 & 593.434 \\
\hline 6 & 2931 & 4.00 & 296.527 \\
\hline 7 & 1800 & 1.17 & 412.708 \\
\hline 8 & 1800 & 6.83 & 421.314 \\
\hline 9 & 1800 & 4.00 & 386.890 \\
\hline 10 & 1800 & 4.00 & 382.587 \\
\hline 11 & 1800 & 4.00 & 399.799 \\
\hline 12 & 1800 & 4.00 & 395.496 \\
\hline 13 & 1800 & 4.00 & 395.496 \\
\hline 14 & 1800 & 4.00 & 404.102 \\
\hline 15 & 1800 & 4.00 & 382.587 \\
\hline 16 & 1800 & 4.00 & 373.981 \\
\hline
\end{tabular}

The regression model results indicated that the quadratic model was the best fit for the $\mathrm{COD}_{\mathrm{Cr}}$ of the papermaking white water. Table 3 shows the significance of the regression model parameters.

Table 3. ANOVA Table of the COD $\mathrm{cr}$

\begin{tabular}{|c|c|c|c|c|c|c|}
\hline \multicolumn{2}{|c|}{ Source } & Sum of Squares & DF & Mean Square & $F$-Value & Critical Value \\
\hline \multirow{7}{*}{} & Model & 96742.11 & 5 & 19348.42 & $F_{2}=186.27$ & $F_{0.05}(5,10)=3.33$ \\
\cline { 2 - 7 } & $x_{1}$ & 90352.86 & 1 & 90352.86 & 869.85 & \\
\cline { 2 - 7 } & $x_{2}$ & 23.28 & 1 & 23.28 & 0.22 & \\
\cline { 2 - 7 } & $x_{1}{ }^{2}$ & 5222.04 & 1 & 5222.04 & 50.27 & \\
\cline { 2 - 7 }$\left(\begin{array}{c}\mathrm{CD}_{c r} \\
(\mathrm{mg} / \mathrm{L})\end{array}\right.$ & $x_{2}{ }^{2}$ & 1069.87 & 1 & 1069.87 & 10.30 & \\
\cline { 2 - 7 } & $x_{1} X_{2}$ & 74.06 & 1 & 74.06 & 0.71 & \\
\cline { 2 - 7 } & $\begin{array}{c}\text { Residual } \\
\text { Lack of } \\
\text { Fit }\end{array}$ & 1038.72 & 10 & 103.87 & & $F_{0.05}(3,7)=4.35$ \\
\cline { 2 - 8 } & $\begin{array}{c}\text { Pure } \\
\text { Error }\end{array}$ & 707.35 & 3 & 102.45 & $F_{1}=0.98$ & \\
\cline { 2 - 8 } & Total & 97780.83 & 15 & & & \\
\hline
\end{tabular}

The ANOVA of the reduced model showed that the fitted model was highly significant, with an $F$-value of 186.27. The lack-of-fit F-value of 0.98 implied that the lack of fit was not significant relative to the pure error. From all these statistical parameter values obtained from ANOVA, it can be concluded that the second-order quadratic model obtained is reliable, stable, and predictable. Following the experimental design presented 
in Table 2, the full quadratic model was simplified and reduced to include only significant terms, as shown in Eq. 1,

$$
y=390.12-106.27 x_{1}-1.71 x_{2}+25.55 x_{1}^{2}+11.56 x_{2}^{2}-4.30 x_{1} x_{2}
$$

where $y$ is the $\mathrm{CODCr}_{\mathrm{Cr}}$ of the papermaking white water $(\mathrm{mg} / \mathrm{L}), x_{1}$ is the $\mathrm{Al}_{2}\left(\mathrm{SO}_{4}\right)_{3}(\mathrm{mg} / \mathrm{L})$, and $x_{2}$ is the PAM $(\mathrm{mg} / \mathrm{L})$.

Interactive effects of the $\mathrm{Al}_{2}\left(\mathrm{SO}_{4}\right)_{3}$ and $\mathrm{PAM}$ on the $\mathrm{COD} \mathrm{Cr}_{\mathrm{r}}$

The combined effect of the $\mathrm{Al}_{2}\left(\mathrm{SO}_{4}\right)_{3}$ and PAM on the $\mathrm{COD}_{\mathrm{Cr}}$ of the papermaking white water is shown in Fig. 2. It was observed that the $\mathrm{COD}_{\mathrm{Cr}}$ of the papermaking white water decreased as the dose of the $\mathrm{Al}_{2}\left(\mathrm{SO}_{4}\right)_{3}$ was increased. This is likely because the $\mathrm{Al}_{2}\left(\mathrm{SO}_{4}\right)_{3}$ contains a large amount of aluminum ions and has a high positive charge density, which can neutralize a large amount of colloidal substances and macromolecular organic substances in the papermaking white water to form flocs. In addition, the paper machine pulp and white water system treated with $\mathrm{Al}_{2}\left(\mathrm{SO}_{4}\right)_{3}$ greatly reduce the colloidal substances, especially in the flow system. Meanwhile, the system will not become dirtier and turbid, and the charge in the system will not become more negative with the closed cycle of white water. The $\mathrm{COD}_{\mathrm{Cr}}$ of the papermaking white water first decreased and then increased as the PAM dosage increased. However, the variation was not significant. This is mainly because after adding the coagulants to the wastewater, an electrical neutralization reaction occurred and the electric double layer on the surface of the particles was compressed, so the colloid lost its stable state (Li 2012).

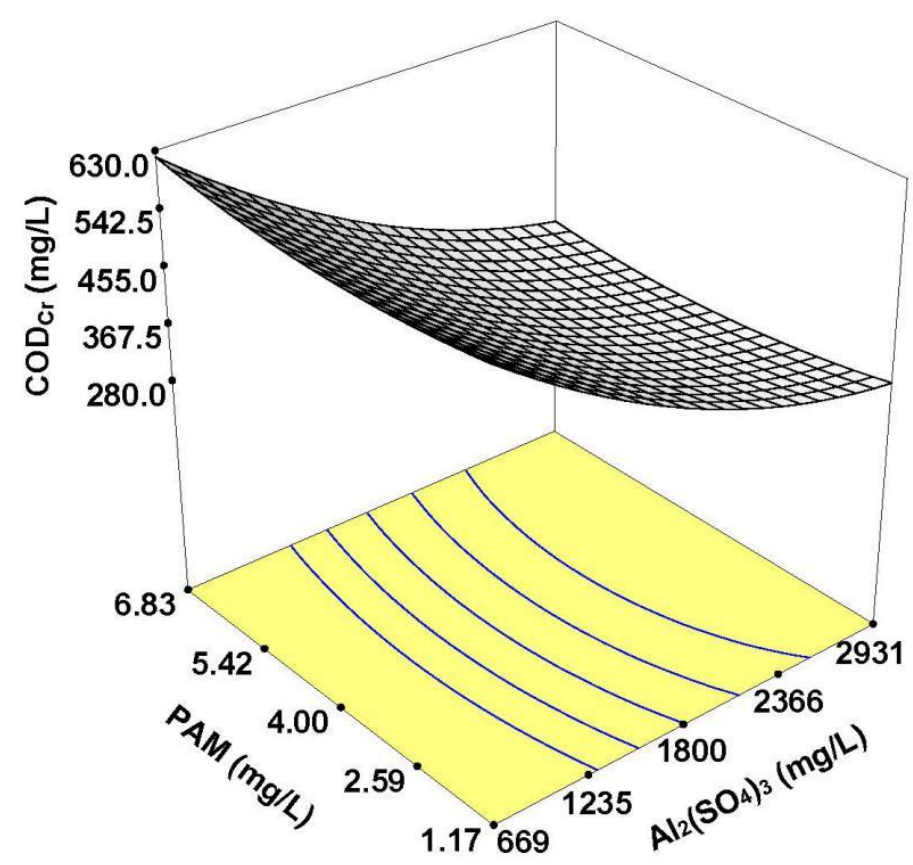

Fig. 2. Effects of the interactive factors on the CODcr

The pollutant particles in the water formed into larger flocs through the effects of adsorption, bridging, net capture, etc. The particles then separated from the water by means of precipitation or air flotation to achieve the purpose of purifying the water (Yazdanbakhsh et al. 2012; Wang et al. 2014; Lindholm-Lehto et al. 2015; Ming 2016). 
According to Fig. 2, the effect of the $\mathrm{Al}_{2}\left(\mathrm{SO}_{4}\right)_{3}$ on the $\mathrm{COD}_{\mathrm{Cr}}$ of the papermaking white water was stronger than that of the PAM based on the ANOVA analysis. The interaction of the $\mathrm{Al}_{2}\left(\mathrm{SO}_{4}\right)_{3}$ and the PAM had a significant effect on the $\mathrm{CODCr}_{\mathrm{Cr}}$ of the papermaking white water. The lowest $\mathrm{COD}_{\mathrm{Cr}}$ of the papermaking white water was achieved at 2,931 $\mathrm{mg} / \mathrm{L}$ of $\mathrm{Al}_{2}\left(\mathrm{SO}_{4}\right)_{3}$ and $4 \mathrm{mg} / \mathrm{L}$ of PAM.

\section{Optimization Analysis}

The optimization experiment was based on the Chinese Standard GB 3544-2008 (2008), the "Discharge standard of water pollutants for pulp and paper industry." This standard refers to the production stability, paper strength up to the standard, and the principles of saving energy, reducing costs, and reducing secondary pollution. Based on the design model, the constraints as previously described, and the graphic optimization using the Design Expert software, the optimum condition were 669 to $2931 \mathrm{mg} / \mathrm{L}$ of $\mathrm{Al}_{2}\left(\mathrm{SO}_{4}\right)_{3}$ and 1.17 to $6.83 \mathrm{mg} / \mathrm{L}$ of PAM (Fig. 3). At the optimum condition, the COD $\mathrm{Cr}$ of the papermaking white water was lower than $300 \mathrm{mg} / \mathrm{L}$, which can meet the requirements of repulping and papermaking of plant fiber mulch sheet.

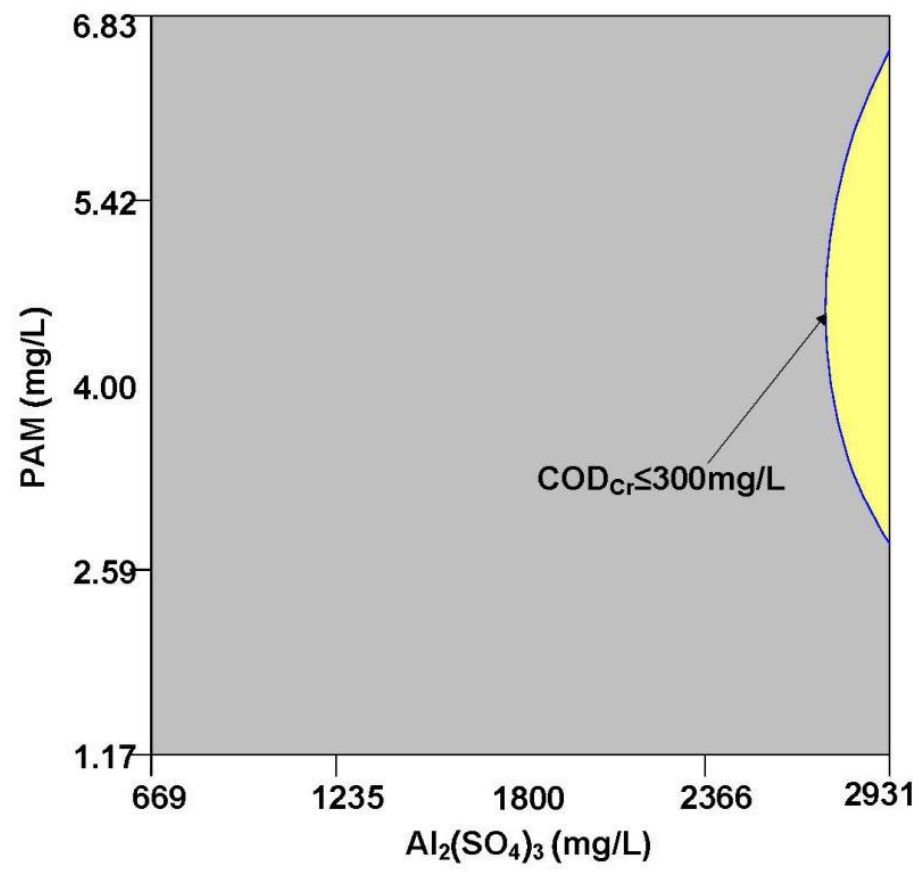

Fig. 3. Optimum analysis of the technology parameters

\section{Model Validation}

The optimum model was validated by testing the $\mathrm{CODCr}_{\mathrm{Cr}}$ of the papermaking white water at $2733 \mathrm{mg} / \mathrm{L}$ of $\mathrm{Al}_{2}\left(\mathrm{SO}_{4}\right)_{3}$ and $4.52 \mathrm{mg} / \mathrm{L}$ of PAM. The $\mathrm{CODCr}_{\mathrm{Cr}}$ of the papermaking white water obtained from the validation experiment was $289.7 \mathrm{mg} / \mathrm{L}$. This agreed with the predicted result, that the $\mathrm{COD}_{\mathrm{Cr}}$ of the papermaking white water was $300 \mathrm{mg} / \mathrm{L}$. Therefore, the optimum condition obtained from response surface methodology design was reliable and applicable, and it indicates that response surface methodology is a powerful tool for system optimization.

\section{CONCLUSIONS}


1. The papermaking white water that was coagulated with $\mathrm{Al}_{2}\left(\mathrm{SO}_{4}\right)_{3}$ exhibited fast settling of flocs, an obvious turbidity removal effect, and a good flocculation effect, which can greatly reduce the cost of water production, and the treated white water can be reused.

2. The $\mathrm{Al}_{2}\left(\mathrm{SO}_{4}\right)_{3}$ coagulant was used in conjunction with the PAM flocculant. The best flocculation conditions were $2,733 \mathrm{mg} / \mathrm{L}$ of $\mathrm{Al}_{2}\left(\mathrm{SO}_{4}\right)_{3}$ and $4.52 \mathrm{mg} / \mathrm{L}$ of PAM when combined to treat the papermaking white water used to produce plant fiber mulch sheet.

3. Under the best flocculation conditions, the CODCr was less than $300 \mathrm{mg} / \mathrm{L}$, which can meet the requirements of repulping and papermaking of plant fiber mulch sheet.

\section{ACKNOWLEDGMENTS}

The authors would like to thank a paper mill in Heilongjiang, China for providing the papermaking white water and the valuable support for the treatment of the papermaking white water.

\section{REFERENCES CITED}

Agarwal, M., Srinivasan, R., and Mishra, A. (2001). "Study on flocculation efficiency of okra gum in sewage waste water," Macromolecular Materials and Engineering 286(9), 560-563. DOI: 10.1002/1439-2054(20010901)286:9<560::AIDMAME560>3.0.CO;2-B

Avci, D., Mol, N., and Dagasan, L. (2002). "New cationic polyelectrolytes for flocculation processes of baker's yeast waste water," Polymer Bulletin 48(4-5), 353359. DOI: 10.1007/s00289-002-0048-5

Ay, F., Catalkaya, E.C., and Kargi, F. (2009). "A statistical experiment design approach for advanced oxidation of Direct Red azo-dye by photo-Fenton treatment," Journal of Hazardous Materials 162(1), 230-236. DOI: 10.1016/j.jhazmat.2008.05.027

Chen, H., Ming, X., Liu, S., Zhang, Y., and Zhang, H. (2015). "Optimization of technical parameters for making mulch from waste cotton and rice straw fiber," Transactions of the Chinese Society of Agricultural Engineering 31(13), 292-300. DOI: 10.11975/j.issn.1002-6819.2015.13.041

Culp, R. L., Wesner, G. M., and Culp, G. L. (1978). Handbook of Advanced Wastewater Treatment, Van Nostrand Reinhold, New York, NY.

Gao, B. Y., Wang, Y., and Yue, Q. Y. (2005). "The chemical species distribution of aluminum in composite flocculants prepared from polyaluminum chloride (PAC) and polydimethyldiallylammonium chloride (PDMDAAC)," Clean - Soil Air Water 33(4), 365-371. DOI: 10.1002/aheh.200300586

Gao, X., and Li, L. X. (2007). "Application of CASS process in papermaking wastewater treatment," Municipal Engineering Technology 4, 267-269.

GB 3544-2008 (2008). "Discharge standard of water pollutants for pulp and paper industry," China Environmental Science Press, Beijing, China.

Huang, M., Ma, Y., Wan, J., Zhang, H., and Wang, Y. (2012). "Modeling a paper-making wastewater treatment process by means of an adaptive network-based fuzzy inference system and principal component analysis," Industrial \& Engineering Chemistry 
Research 51(17), 6166-6174. DOI: 10.1021/ie203049r

Hubbe, M. A., Metts, J. R., Hermosilla, D., Blanco, M. A., Yerushalmi, L., Haghighat, F., Lindholm-Lehto, P., Khodaparast, Z., Kamali, M., and Elliott, A. (2016).

"Wastewater treatment and reclamation: A review of pulp and paper industry practices and opportunities," BioResources 11(3), 7953-8091. DOI:

10.15376/biores.11.3.Hubbe

Li, F., Jiang, J. Q., Wu, S., and Zhang, B. (2010). "Preparation and performance of a high purity poly-aluminum chloride," Chemical Engineering Journal 156(1), 64-69. DOI: 10.1016/j.cej.2009.09.034

Li, H. J. (2012). "Study on the current situation and countermeasures of flocculants in wastewater treatment," Environmental Protection and Circular Economy 32(06), 5356.

Lindholm-Lehto, P. C., Knuutinen, J. S., Ahkola, H. S. J., and Herve, S. H. (2015). "Refractory organic pollutants and toxicity in pulp and paper mill wastewaters," Environmental Science and Pollution Research 22(9), 6473-6499. DOI: 10.1007/s11356-015-4163-X

Lüeddeke, F., Heb, S., Gallert, C., Winter, J., Güede, H., and Löeffler, H. (2015). "Removal of total and antibiotic resistant bacteria in advanced wastewater treatment by ozonation in combination with different filtering techniques," Water Research 69, 243-251. DOI: 10.1016/j.watres.2014.11.018

Mänttäri, M., and Nyström, M. (2010). "Water treatment in the pulp and paper industry," in: Membrane Technology: Volume 4: Membranes for Water Treatment, K.-V. Peinemann and S. P. Nunes (eds.), John Wiley \& Sons, Hoboken, NJ, pp. 169-192.

Mänttäri, M., Kallioinen, M., and Nyström, M. (2015). "Membrane technologies for water treatment and reuse in the pulp and paper industries," in: Advances in Membrane Technologies for Water Treatment, A. Basile, A. Cassano, and N. K. Rastogi (eds.) pp. 581-603.

Ming, X. (2016). Study on Manufacturing Key Technologies of Waste Cotton FiberBased Agricultural Mulching, Master's Thesis, Northeast Agricultural University, Harbin, China.

Ming, X., and Chen, H. (2020). "Experiment on cultivation performance of plant fiberbased degradable film in paddy field," Applied Sciences 10(2), 495. DOI: 10.3390/app10020495

Ming, X., Chen, H., and Wang, D. (2019). "Optimization of processing parameters to increase thermal conductivity of rice straw fiber film," Applied Sciences 9(21), 4645. DOI: $10.3390 /$ app9214645

Montgomery, D. C. (2017). Design and Analysis of Experiments, John Wiley \& Sons, Hoboken, NJ.

Ravikumar, K., Pakshirajan, K., Swaminathan, T., and Balu, K. (2005). “Optimization of batch process parameters using response surface methodology for dye removal by a novel adsorbent," Chemical Engineering Journal 105(3), 131-138. DOI:

10.1016/j.cej.2004.10.008

Rayne, S., and Ikonomou, M. G. (2015). "Polybrominated diphenyl ethers in an advanced wastewater treatment plant. Part 2: Potential effects on a unique aquatic system," Journal of Environmental Engineering and Science 4(5), 369-383. DOI: 10.1139/s04067

Sen, R., and Swaminathan, T. (2004). "Response surface modeling and optimization to elucidate and analyze the effects of inoculum age and size on surfactin production," 
Biochemical Engineering Journal 21(2), 141-148. DOI: 10.1016/j.bej.2004.06.006

Senta, I., Matošić, M., Jakopović, H.K., Terzic, S., Curko, J., and Mijatović, I. (2011). "Removal of antimicrobials using advanced wastewater treatment," Journal of Hazardous Materials 192(1), 319-328. DOI: 10.1016/j.jhazmat.2011.05.021

Shi, F. Y. (2010). "Design and debug on regenerated papermaking wastewater treatment project," Environmental Science \& Technology 33(7), 168-173.

Shi, S. L., and He, F. W. (2003). Analysis and Detection of Pulping and Papermaking, Chinese Light Industry Press, Beijing, China.

Sui, Z. H., Liu, A. J., and Zhao, X. (2007). "Study on treatment of papermaking wastewater with cationic polymer flocculant," Transactions of China Pulp \& Paper 22(3), 52-56.

Sun, W., Zhu, H., Sun, Y., Chen, L., Xu, Y., and Zheng, H. (2018). "Enhancement of waste-activated sludge dewaterability using combined Fenton pre-oxidation and flocculation process," Desalination and Water Treatment 126, 314-323. DOI: 10.5004/dwt.2018.23076

Tavares, A. P. M., Cristóvão, R. O., Loureiro, J. M., Boaventura, R. A. R., and Macedo, E. A. (2009). "Application of statistical experimental methodology to optimize reactive dye decolourization by commercial laccase," Journal of Hazardous Materials 162(2-3), 1255-1260. DOI: 10.1016/j.jhazmat.2008.06.014

Toczyłowska-Mamińska, R. (2017). "Limits and perspectives of pulp and paper industry wastewater treatment - A review," Renewable \& Sustainable Energy Reviews 78, 764-772. DOI: 10.1016/j.rser.2017.05.021

Toyoda, S., Suzuki, Y., Hattori, S., Yamada, K., Fujii, A., Yoshida, N., Kouno, R., Murayama, K., and Shiomi, H. (2011). "Isotopomer analysis of production and consumption mechanisms of $\mathrm{N}_{2} \mathrm{O}$ and $\mathrm{CH}_{4}$ in an advanced wastewater treatment system," Environmental Science \& Technology 45(3), 917-22. DOI: 10.1021/es $102985 \mathrm{u}$

Wang, B., Gu, L., and Ma, H. (2007). "Electrochemical oxidation of pulp and paper making wastewater assisted by transition metal modified kaolin," Journal of Hazardous Materials 143(1-2), 198-205. DOI: 10.1016/j.jhazmat.2006.09.013

Wang, H., Gong, Q., Huang, H., Gao, T., Yuan, Z., and Zhou, G. (2018). 'P-n heterostructured $\mathrm{TiO}_{2} / \mathrm{NiO}$ double-shelled hollow spheres for the photocatalytic degradation of papermaking wastewater," Materials Research Bulletin 107, 397-406. DOI: 10.1016/j.materresbull.2018.08.016

Wang, H., Jiang, W., Gu, L., and Ma, S. (2014). "Experimental study on the treatment of wastewater from food waste by a new type of internal circulation reactor," Industrial Water Treatment 48(6), 409-419.

Wang, H., Yu, G., Liu, G., and Pan, F. (2006). "A new way to cultivate aerobic granules in the process of papermaking wastewater treatment," Biochemical Engineering Journal 28(1), 99-103. DOI: 10.1016/j.bej.2005.10.002

Wang, Y., Chen, K., Mo, L., Li, J., and Xu, J. (2014). “Optimization of coagulationflocculation process for papermaking-reconstituted tobacco slice wastewater treatment using response surface methodology," Journal of Industrial and Engineering Chemistry 20(2), 391-396. DOI: 10.1016/j.jiec.2013.04.033

Watkinson, A. J., Murby, E. J., and Costanzo, S. D. (2007). "Removal of antibiotics in conventional and advanced wastewater treatment: Implications for environmental discharge and wastewater recycling," Water Research 41(18), 4164-4176. DOI: 10.1016/j.watres.2007.04.005 
Wei, H. L. (2016). "Case study on environmental impact assessment of paper mill wastewater reuse," Light Industry Science and Technology 32(11), 90-94.

Wu, S., Yue, Q., Qi, Y., Gao, B., Han, S., and Yue, M. (2011). "Preparation of ultralightweight sludge ceramics (ULSC) and application for pharmaceutical advanced wastewater treatment in a biological aerobic filter (BAF)," Bioresource Technology 102(3), 2296-2300. DOI: 10.1016/j.biortech.2010.10.057

Xie, Y. M., Qu, F., Wang, L., Liu, J., Yang, H. T., and Yao, L. (2012). “Development and application of new technology of pulping \& papermaking wastewater treatment," Transactions of China Pulp and Paper 27(3), 56-61.

Yang, D. M., and Wang, B. (2010). "Application of advanced oxidation processes in papermaking wastewater treatment," China Pulp \& Paper 29, 69-73.

Yazdanbakhsh, A., Mahdipour, F., Ghanbari, F., Zamani, A., Sharifimaleksari, H., and Safdari, M. (2012). "Survey and comparison of aluminum sulfate and poly aluminum chloride (PAC) in olive oil mill wastewater treatment," The Journal of Toloo-ebehdasht 11(2), 98-106.

Yeon, K. M., Park, J. S., Lee, C. H., and Kim, S. M. (2005). "Membrane coupled highperformance compact reactor: A new MBR system for advanced wastewater treatment," Water Research 39(10), 1954-1961. DOI: 10.1016/j.watres.2005.03.006

Zhan, X., Gao, B., Yue, Q., Wang, Y., and Wang, Q. (2010). "Coagulation efficiency of polyaluminum chloride for natural organic matter removal from low specific UV absorbance surface water and the subsequent effects on chlorine decay," Chemical Engineering Journal 161(1-2), 60-67. DOI: 10.1016/j.cej.2010.04.023

Zhao, B. J., Shen, H. T., Fang, J. Q., Qiu, H., and Li, Z. P. (2016). “Application of dual membrane system in the treatment of papermaking waste water," China Pulp \& Paper 35, 47-51. DOI: 10.11980/j.issn.0254-508X.2016.09.009

Zhao, L. J., Zhang, Y. F., Hong, J. F., and Tu, W. W. (2014). "Papermaking wastewater treatment - A brief review," Advanced Materials Research 926-930, 4276-4279. DOI: 10.4028/www.scientific.net/AMR.926-930.4276

Article submitted: September 7, 2020; Peer review completed: November 21, 2020; Revised version received: November 30, 2020; Published: January 6, 2021.

DOI: 10.15376/biores.16.1.1382-1393 